\title{
EXPLORING INCLUSION AND DIVERSITY WITHIN UNDERGRADUATE TEACHER TRAINING PROGRAMMES IN ENGLAND
}

\author{
C. Devarakonda', S. McGrath ${ }^{2}$, D. Chaudhary ${ }^{3}$ \\ University of Chester (UNITED KINGDOM)
}

\begin{abstract}
This research has been triggered by the consistent references to the increase in the number of children from ethnically diverse population in schools in England and lack of confidence and preparedness of teachers to teach children from diverse backgrounds. A government commissioned Newly Qualified Teachers (NQT) survey encouraged them to respond to questions related to their preparedness and confidence to teach children from all ethnic backgrounds and who have English as additional language, one year after gaining their Qualified Teacher Status (QTS).
\end{abstract}

The aim of this research is to explore the perspectives and challenges of students (referred to as Associate teachers (ATs)) on teacher training programmes related to their knowledge and understanding of inclusion and diversity from the teacher training programmes. This research examined the perceptions of ATs on their final year of the three-year degree on initial teacher education programme and some teacher educators teaching this cohort of students who are programme leaders, year leaders, and other staff, who provide enriching experiences related to diversity.

Data was collected through a survey consisting of open questionnaires for teacher educators and ATs were requested to volunteer to respond to questions on an online forum. The online survey was kept open for a short window of four weeks to enable ATs to respond in their own time and ensure anonymity.

The responses provided by ATs and Teacher Educators (TEs) have been analysed using qualitative data analysis applying the three steps - Developing and Applying Codes, identifying themes, patterns and relationships and summarizing the data. The data resulted in four themes : concepts and contexts of diversity, experiences on the programme, preparedness to teach and challenges. The ATs and TEs articulate that there was significant impact of the teacher training programme on preparing them to teach children from diverse ethnic backgrounds. They acknowledged the lack of diversity in the placements to teach children from diverse backgrounds as one of the key challenges and barriers faced.

Keywords: Inclusion and diversity - perceptions, Teacher education, children from ethnically diverse backgrounds, curriculum

\section{INTRODUCTION}

Diversity in the contemporary society is changing rapidly due to mobility inside Europe, international migration as a result of globalisation and an increase in refugees, asylum seekers [1]. This led to an increase in the diversity of school population and consequently expectation upon teachers to meet the unique needs of all children. European Commission reported that 'In spite of the diversity of pupils' backgrounds, teachers remain largely homogenous and lacks expertise and confidence in teaching diverse schools. Teachers feel ill prepared to teach students from diverse socioeconomic, cultural and linguistic backgrounds' [2: p.20].

The Newly Qualified Teachers' Survey (NQT) survey (2018) has reported on the extent to which their initial teacher training (including school placements) prepared participants for teaching, and gathered data to record NQTs' confidence to, 'Teach across all ethnic backgrounds' (53\%) and' Teaching pupils with English as an Additional Language' (39\%) [3].

Burns and Shadoian-Gersing stated that the concept of diversity is 'multifaceted' and referred to ' characteristics that can affect the specific ways in which developmental potential and learning potential are realised including cultural, linguistic, ethnic, religious and socio- economic differences. [4: p.21]

Diversity has been perceived in several ways. UNESCO has defined the diversity from the perspective of inclusion '....as a process of addressing and responding to the diversity of needs of all learners through increasing participation in learning, cultures and communities, and reducing exclusion within 
and from education. It involves changes and modifications in content, approaches, structures and strategies, with a common vision which covers all children of the appropriate age range and a conviction that it is the responsibility of the regular system to educate all children. " [5: p.13].

European Commission report defined diversity as 'individuals' migrant and/or minority background. These include first and subsequent generations of EU and third country migrants, asylum seekers and refugees, as well as national and regional ethno-cultural, linguistic and religious minorities' [2: p.14].

\section{Broad Perspective of diversity}

As a social construct, the concept of diversity differs from person to person as it is susceptible to multiple interpretations [2]. The research study carried out by Burner, Nodeland \& Aamaas (6) reflected the viewpoint of teacher educators and school teachers about diversity in education in Norway. Their findings reflected the difference in level of operationalization: as teacher educators were talking from the point of view of students experiences whereas school teachers from their own experiences. Teacher educators defined diversity in much more open and broader aspect of multiculturalism and multilingualism which includes openness in attitude, opinions, religion and cultures. In contrast, school teacher's perceived diversity as the reflection of difference revealing their concrete view prominently talked about religion and language as relatively important for understanding diversity.

\section{Complexity of Identities}

The concept of identity for ATs is more about their own individual experiences of diversity, linked to their own ethnicity [7]. Furthermore, the ATs signposted physical differences as markers of identity and identified potential challenges associated with racialized identities. These identities claimed to have a negative impact on their lives and their educational experiences as they have to behave consistently in a stereotypical way, and the situation becomes complex when the concept of identity of students merges with their family background and parents understanding of diversity [7].

Cardona Molto et al., (8) broadly differentiated the responses of the university students from Spain, England and the United States into relativist and ethnocentric views and stated that students with a relativist point of view have a more positive attitude towards diversity and differences than ethnocentric students. These differences and diversity as revealed by Dunne et al., (9) have induced a sense of discomfort among trainee teachers. They hesitate in revealing their feelings about the situation as talking about differences on the basis of race and ethnicity will offend others. Bhopal et al., argued that trainee teachers don't feel confident and well equipped to handle diversity induced situations and incidences, whether they are racial or ethnic. To be more equipped trainee teachers demanded more practical sessions and lectures on diversity [7].

\section{Dealing with Diversity Issues}

All of the studies included for literature synthesis revealed that issues related with diversity are high on policy priority, and measures in attitude change have become tool for change [6, 8-10]. As a way of working with diversity, teacher educators from Norway suggested to actively draw attention on the prior experiences and background of the students, to start working on diversity within the classroom of ATs [6]. Furthermore, teacher educators suggested classroom arrangements at schools by focusing on language, involving mother tongue teachers for EAL students [6]. Teacher educators and education programme need to emphasise the teaching of tolerance and acceptance for ATs including raising acceptance level for multiculturalism Cardona Molto et al., (8) and Dunne et al., (9) further argued that, the education programme needs to focus on ethnic minority children and teach the teacher trainees along with SEN and EAL to broaden their horizon of acceptability. The societies have become more diverse and the counter effort from education programme is to induce qualities to include understanding, tolerance, respect, empathy, openness in future teachers [6].

\section{Context of the research}

This research was conducted by a team working in the Initial Teacher Education (ITE) programme, at a university based in the North West of England. The University is located in the Northwest region of England, which has a predominantly white population with somewhat limited ethnic and religious diversity. Where there are diverse communities these are well established Gypsy Roma Traveller (GRT) communities, Polish and other Eastern European communities with Syrian refugees emerging as relatively new communities, and in the larger towns and cities well established BME populations. The 
Partnership region is diverse Socio-economically and includes settings catering for the wealthiest and also most deprived areas within the region. The Initial Teacher Education Programme at the University covers a geographical area across the North-west of England, North Wales and towards the Midlands. Approximately 500 Nurseries, Primary, Secondary schools and other educational settings are engaged in Partnership with the faculty to provide placement experiences and to develop teaching experience.

The diversity of pupils/children enrolled in the nursery, Primary, secondary schools and other educational settings who are engaged in Partnership within the ITE programme included

- 20 schools with more than $15 \%$ EAL pupils.

- 143 schools $15 \%$ (15-55\%) of pupils from low socioeconomic status [Free School Meals(FSM)]

- 22 schools with over 15\% SEN/D pupils recorded (ranging from 15\% to 100\%). (Departmental data).

The aim of this research is to explore the perspectives and challenges of students (referred to as Associate teachers (ATs) on teacher education programmes related to their knowledge and understanding of inclusion and diversity from the teacher education programmes. This research examined the perceptions of ATs on their final year of the three-year degree on initial teacher education programme and some teacher educators teaching this cohort of students who are programme leaders, year leaders, and other staff, who provide enriching experiences related to diversity.

\section{The objectives of this study are:}

- To explore the current practice within Undergraduate programmes in relation to inclusion and diversity, in the undergraduate teacher training programmes.

- To exploring perceptions of (final year) Associate Teachers in relation to their understanding and experiences of diversity whilst on their programme.

- To identify the innovative and evolving practices that embeds diversity and inclusion within the teacher training programmes.

\section{METHODOLOGY}

This research explored the perceptions of ATs about their experiences around inclusion and diversity using an online survey and focus group discussion to gain the responses from ATs and TEs. The sample of this research study consists of Teacher Educators (TE) and Associate Teachers (ATs) on their final year of the three-years on the Initial Teacher Education Programme. The data was collected from seven TEs and Nineteen ATs who were willing and agreed to participate in the research. A Focus Group Discussion (FGD) and survey questionnaires were used to collect data for the research.

\section{Ethical Considerations}

This research project followed ethics protocol, procedures and requirements, by seeking approval from the Faculty Ethics committee. Following the institutional ethical approval, informed consent was also obtained from all the participants (ATs and TEs). The participants (ATs) confirmed their consent by ticking the box before proceeding to respond to the online survey and verbal consent was obtained from TEs before the FGD. Participation was voluntary and they were also informed about their rights to not to answer all the questions and to abstain from participating in the study or to withdraw anytime if they felt uncomfortable in continuing with the study.

\section{Data Collection}

The data collection was conducted in two phases. First phase related to recruiting ATs in the research. The ATs were informed about the research and shared the aims and objective of the research at the end of one of their session after getting approval from programme leader and year leader. The online survey was kept open for short window of few weeks to encourage the ATs to respond at their convenience along with maintaining the anonymity. The participant information sheet containing the aims and objectives of the research along with the questionnaire was shared online. The questionnaire asked the questions about the understanding and perception of the inclusion and diversity, challenges faced and how confident are teacher trainee to teach in a diverse school environment in open responses. 
In the Second phase, information regarding the FGD was shared within the faculty and seven TEs volunteered to participate in the FGD. Based on the themes that emerged from literature review and discussion among the research authors, the semi-structured open-ended questions were designed. The questionnaire was designed to capture elaborate responses of the participants. The FGD lasted for approximately 90 minutes. The interview guide and prompt questions were used by the author to collect information from FGD with extensive clarification and deep understanding. The FGD was audiorecorded after receiving the consent from the participants, and interview notes were also made. This audio recording was transcribed and interpreted soon after the FGD by the authors.

\section{Data Analysis}

The analysis of the two sets of the collected data, from online survey questionnaire and FGD, was done by the research team. The responses and general observations were discussed to explore and understand the meaning. A three step approach of qualitative data analysis - Developing and Applying Codes, identifying themes, patterns and relationships and summarizing the data was employed to analyse the data [11].

This research followed the qualitative data analysis approach which involves reading and re-reading of the transcribed and survey data sets to allow data familiarization and to acquire a general feeling for experiences and providing attention to inferences, word choices and other elements of languages [12].

The research team listed, sorted and extracted significant statements from data sets and initial coding framework was developed. Throughout the research study, the coding framework was evolved. Through rigorous reassessment and discussion within the research team, the codes were further refined and arranged into themes and sub-themes. NVIVO v.11 was used for data management.

The themes that emerged following the data analysis are discussed further in the results section.

\section{RESULTS AND DISCUSSION}

Following the rigorous analysis of responses to the online survey and focus group discussion, the research team developed the following themes and codes.

3.1 Concepts and contexts of diversity - codes - Attributes and characteristics, contexts of diversity, Impact of training and policies

Following the rigorous analysis of responses to the online survey and focus group discussion, the research team developed some themes and codes.

The need to address issues of diversity in education has become more important than ever in light of the increased globalization, international migration and an increase in refugees, asylum seekers. This has led to school communities becoming increasingly diverse and the expectations of the teacher workforce to meet the unique needs of all children has mirrored this.

The responses provided by ATs related to the concept of diversity and led to three codes Attributes, contexts of diversity and impact of training and policies.

The first code related to attributes and characteristics of diversity that were listed to explain diversity.

"mix of ethnicities, genders, ages and disabilities" (AT4)

"...each person being unique and having different characteristics" (AT13)

"diversity means similarities and differences.... ATs need to explore reflectively two questions in relation to diversity of their classrooms- ... $1^{\text {st }}$ is the nature of similarity and differences and $2^{\text {nd }}$ is the extent of similarity and differences" (TE1)

These groups included ethnicity, gender, age, disabilities, race, religion, Gypsy Roma and travellers families etc. It can be noted that these categories are visible. Paine (13) proposed four orientations to diversity as individual difference, categorical difference, contextual difference, and pedagogical difference. Individual difference has been explained as the world is seen as full of people who differ in all sorts of ways and on all sorts of dimensions. The individual differences in the categories listed by 
the students are those they are familiar with. One staff member also referred to diversity based on the protected characteristics in the Equality Act 2010 [14].

TEs on the other hand, defined diversity elaborately relating to recognition of differences, nature and extent of the similarities and differences in the perceptions of diversity and acknowledgement of differences, and commonalities between groups.

Contexts of diversity in the community influences the concepts of diversity. It has been noted from the data that diversity has been perceived on the basis of familiar and visible differences such as skin colour, facial features, ability or inability to speak majority language/s as mother tongue or first language especially English in England, disadvantage on the basis of economic status, area in which they live, religion they identify with, gender and sexuality. The perspectives of diversity have also been evolving with changing contexts. For example, one TE referred to the Irish community in Britain as diverse and that they were subjected to discrimination until 1980 s, but the focus has now shifted to other economic migrants from Eastern Europe and refugees and asylum seekers from war torn countries,.

\section{Impact of training and policies}

An understanding of diversity is also influenced by the current legislation and policies emphasised by the government, and consequently emphasised through teacher education programme design, delivery and content. For example, Equality Act 2010, Prevent Duty and British values has been influential in understanding and conceptualising diversity. The legislation and policies related to diversity and inclusion have raised awareness in professionals, practitioners, TEs, ATs regarding ethnic diversity, EAL, religious diversity and GRT communities. Policies have encouraged.

\subsection{Experiences on the Programme - codes - raised awareness, application of knowledge through practice}

There is an apparent tension between programme content delivery in relation to diversity (EAL strategies in particular), and AT's perceived opportunities to realise this through practice during their teaching placements, and where this is not the case confidence is only expressed regarding two specific ethnic groups (GRT and Muslim students). This perception of 'visible' diversity is echoed by teacher educators who also identify a lack of ethnic diversity within the partnership as one of the challenges they encounter (unique to this partnership). Where ATs do not perceive their teaching practice has been in diverse settings the tension remains, and theory remains detached from practice. It is clear from the participants responses that all sessions though well received and valued, reinforce the concept of isolated practice or strategies specific to a particular group and do not identify transferable skills or approaches that could be applied for other learners/ contexts.

"the strategies looked at in university sessions have shown me the different ways teachers can include all children..." "...having more sessions on how to include learners should run through the BA course more..." (AT6)

In some cases it is the level of interest, subject nature or priority placed on diversity by the TE that influences the programme content and the regularity of input on this subject which in turn impacts on ATs perception and experience alongside school practice. For example one TE delivers an enrichment programme which covers a wide range of religions and visits to places of worship. This experience enables ATs to question, explore and gain a deeper insight prior to their own delivery in schools and provides real life experience from which ATs can draw and reflect before embedding in their teaching.

In some cases 'enrichment' is more driven by students identifying gaps in knowledge and experience and ensuring these are 'covered' and assessed as part of their summative assessments against the Teaching Standards [15]. This may mean that for a short period ATs will attend settings and schools to gain intensive experience against priority areas. Often these also include EAL experience, SEND experience or additional work in key stage one delivering a phonics programme for example. These stand alone, distinct experiences again can become tokenistic in terms of consolidating cohesive practice.

Raised awareness of diversity through modules. The responses of both TEs and ATs seems to be similar although staff seemed to have included more details with regard to what is included in the modules and placements. ATs unanimously indicated $100 \%$ improved awareness of diversity and inclusion as a result of university programme delivery. Given the low levels of diversity within our student population it is entirely possible that this comes from a widening of their awareness of 'the other' and 
perhaps an awareness of approaches and significant factors for groups to which they do not themselves belong or identify given the predominance of one ethnic group within the cohort. ATs also reinforced through their responses that university sessions had been instrumental in improving their understanding of specific inclusive strategies and approaches for all learners, such as children with EAL (and children with SEND)

"Specific training prior to placement example safeguarding and PREVENT strategy to support SEN and EAL pupils..." (AT18)

ATs placed high value on external speakers who also delivered seminars on specific groups such as GRT, and this in turn often encouraged some independent study and reflection into other diverse groups such as different religious groups. Other inputs (such as input from the Dean on LGBTQ) and additional sessions on BME pupils also highlighted inclusive practices, all within a wider agenda to understand and promote fundamental British values (mutual respect and tolerance of difference).

TEs also referred to these different modules that integrated issues around diversity and also placement based modules to teach diverse children. This was also reinforced by school based tasks to be undertaken to reinforce theory with real experience (when possible).

"before their school-based learning, the students had a second 'programme level training and awareness' (in a level 6 SBL module) about PREVENT and British Values" (TE3)

As part of statutory training ATs are also expected to take an online training programme that raises awareness about Prevent duty and British values within the safeguarding training framework (as are University colleagues).

\subsubsection{Application of knowledge through practice}

Over the last 5 years, the Partnership has grown rapidly and increased in geographical area. This also includes some large cities and towns with diverse population. There are still relatively limited opportunities for ATs to experience teaching pupils from a wide range of diverse communities.

In selecting appropriate settings for teaching placements there is an assessment made on the level of 'contrast' between school placements to determine an ATs journey and experience is a broad as possible. The partnership team compare and analyse the following key characteristics of a school to determine the appropriateness of a placement in facilitating this experience. The selection of placements is influenced by the following criteria: percentage of EAL, FSM, SEND, school size/pupil number, and OFSTED/ESTYN category)"

\subsection{Preparedness to teach - codes - layers of tokenism, visible and invisible layers of diversity}

The introduction of Teachers' Standards in September 2011 has set up national benchmarks for teacher trainees within the profession [15]. Expectations to meet the standards has compartmentalised teaching practice and focussed on meeting standards in isolation rather than as cohesive practice reflecting the diversity in contexts. In relation to diversity specifically, this could have also encouraged a tokenistic approach to training and experiences, where diversity becomes something to be covered in the modules and, assessed in isolation. This is supported by a trend of underperformance of ATs against standards which touch upon ensuring effective support, provision and outcomes for pupils with diverse needs (such as Teacher's Standard 5 Adapt teaching to respond to the strengths and needs of all pupils [15]

- have a clear understanding of the needs of all pupils, including those with special educational needs; those of high ability; those with English as an additional language; those with disabilities; and be able to use and evaluate distinctive teaching approaches to engage and support them [15].

This dominance of assessment over organic experience and development is echoed by a TE, "the problem is there are things that are implicit and suffuse our experience- for example an exploration of S5 and the development of provision within school experience"

Measures have also been taken to attempt to replicate experience in the guise of additional tasks to be undertaken during a school based learning placement $(\mathrm{SBL})$ where there are limited or no EAL pupils to work with, and are based on 'case studies' of EAL learners.

"From university session we have looked in startegies to include all learners such as children with EAL and children with SEND. Looking at EAL strategies have been most beneficial to 
understand how to support children with EAL as I have not been on a placement with many children with EAL in my base class" (AT6)

Planning for diverse / EAL learners might encourages a singular or, an oversimplification of approach or encouraging labelled category of learners to be perceived as a homogeneous group. Without an opportunity to contextualise these approaches and/or an experienced mentor to support, practice to meet needs of diverse learners consider analyse and synthesise there remains a detachment between theory and practice and an emphasis on a tick box exercise to experiences and assessment against the teacher's standards as episodic practice rather than a holistic approach.

3.4 Challenges - codes - institutional, external forces

3.4.1 Institutional: Main challenges referred to by the ATs seemed to focus on their confidence and skills to be able to teach children from diverse backgrounds. The responses of TEs seem to be focusing on time to focus on a wide range of issues in the programme content.

One of the TE questioned

“...or do we respond to Government policy and agendas, meaning vital area of diversity are currently ignored or not given sufficient time needed for coverage, awareness and training on the programme" (TE3)

"...challenges also include those outlined above: expertise (related support in terms of this), funding (to get speakers, support etc.)" (TE5).

"Time, time and more time- there seems to be no space in the programmes for many of these experiences to be available wider." (TE6)

Challenges perceived by ATs:

"Ensuring that children recognise and acknowledge differences between themselves and others in school. 2. Teaching children to be tolerant (aware and respectful of differences). 3. Teaching in areas different to Chester (majority white, British)" (AT14)

"My main challenge will be when I get children with EAL in my class as I haven't had experience before; I've only been given strategies in university." (TE6)

Impact of the PREVENT strategy, on teacher education. It has been widely criticized for highlighting specific groups for scrutiny. In 2015, Prevent became law, enforcing a duty on all schools and settings to prevent young people being drawn into terrorism [16]. This has now become part of a ATs mandatory training, often integrated or part of safeguarding training.

"before their school-based learning, the students had a second 'programme level training and awareness' (in a level 6 SBL module) about PREVENT and British Values... Diversity is explored within that input too... The students also complete the online Government PREVENT training to enhance their subject knowledge as well as pedagogic knowledge previously outlined."(TE3)

3.4.2 External forces: The influence of the wider media on ATs perception of diversity and inclusion cannot be underestimated. In a post-Brexit Britain, there has been an increase in the media of scrutiny and stereotyping of specific groups and faiths. A TE recognised the importance of ensuring wider understanding for marginalised groups.

"In the past we have done religious diversity with the whole range of students in the PGCEstudents really valued the opportunity to discuss the Muslim experience of education and Britain... there seems to be no space in the programmes for many of these experiences to be available wider." (TE3)

One of the ATs believed ' 
"I think the main challenge as a future teacher in terms of inclusion and diversity is the children's awareness of media and news influences. With the challenges and hostility that is portrayed in the news, I believe this will be one of the most challenging aspects to face." (TE18)

\subsection{Model of awareness of diversity}

Based on the findings of this research study relating to perceptions of ATs and TEs about diversity, we have adapted Johari Window model (17) to develop an understanding of challenges to relate to the perspectives of diversity. This model can be used to raise awareness of ATs and TEs about what is known by and unknown by self and others.

Table 1. Model of awareness of diversity

\begin{tabular}{|l|l|l|}
\hline \multicolumn{1}{|c|}{ Known by Self } & \multicolumn{1}{|c|}{ Unknown by self } \\
\hline $\begin{array}{l}\text { Known By } \\
\text { others }\end{array}$ & $\begin{array}{l}\text { Open and free (Stereotypes and } \\
\text { prejudices) what do we know, are we } \\
\text { open and flexible to adapt to new } \\
\text { information } \\
\text { Visible diversity - what is politically } \\
\text { correct, attitudes to diverse } \\
\text { population }\end{array}$ & $\begin{array}{l}\text { Blind spot- you are prejudiced and do not } \\
\text { necessarily believe you are prejudiced } \\
\text { Religious diversity, ethnic minorities, EAL, } \\
\text { Gypsy Roma and Traveller families } \\
\text { Perceived by others (especially by the } \\
\text { members of diverse communities) }\end{array}$ \\
\hline $\begin{array}{l}\text { Unknown } \\
\text { By others }\end{array}$ & $\begin{array}{l}\text { Façade or Mask (Hidden) - you are } \\
\text { prejudiced - but do not like to admit } \\
\text { your prejudices because of the } \\
\text { stereotypes they were not acceptable } \\
\text { in the society } \\
\text { Attitudes towards specific diverse } \\
\text { groups - Gypsy Roma and Traveller } \\
\text { families, ethnic minority groups, } \\
\text { specific religions. }\end{array}$ & $\begin{array}{l}\text { Unknown by self and others - you do not } \\
\text { know some of the stereotypes because it is } \\
\text { unconscious. } \\
\text { Invisible diversity - ingrained in the society, } \\
\text { lack of awareness, } \\
\text { Perceived by others (especially by the } \\
\text { members of diverse communities) }\end{array}$ \\
\hline
\end{tabular}

\section{CONCLUSIONS}

Largely, ATs experience is dependent on two key factors- the school experience and the importance and emphasis that TEs place on diversity within university sessions and programme content and delivery. Whilst both ATs and TE perceive there is a paucity of diversity in the area in terms of ethnic diversity there is far more than is appreciated and requires further understanding than a simple 'visible' identity that can be easily identified. There is almost a self-imposed limit to ATs expectations of their school based experience informed by this perception, and a willingness to take on face value the visible identity of those schools and communities. This is evident in the apparent contradiction of the survey which indicates in spite of the value placed by ATs on the sessions at university and their perceived improvement in their understanding and appreciation of diversity, they still report a lack of confidence to teach in diverse settings to teach in diverse settings (as previously indicated this speaks to ethnic diversity predominantly and not other definitions which could indicate a setting was diverse).

Challenges - it is significant that many of the TEs indicate that time and an overcrowded programme often determines the level of attention paid to this subject. Likewise changing government agendas and the TEs own confidence with the subject matter can also influence and become a challenge to ensuring equity of experience and a comprehensive approach to diversity in teaching programmes.

It is apparent from this project that when discussing ethnic diversity, the emphasis is predominantly on understanding and supporting pupils or whom English is an additional language. This tends to be the focus and preoccupation for ATs. What has been given less importance is understanding the issues of representation, access and equity for pupils who are BME. There appears to be relatively little focus 
given to this, yet BME pupils are persistently identified as underachieving in comparison to their peers across key stage 2-4, and more recently it was revealed, at university level.

\section{ACKNOWLEDGEMENTS}

This study was supported by a QR grant fund from the University of Chester. Our most sincere thanks go to all the participants for their participation and valuable insights to this study.

\section{REFERENCES}

1. Hollins ER, Guzman MT. Research on preparing teachers for diverse populations. Studying teacher education: The report of the AERA panel on research and teacher education. 2005 Jun 1;477:548.

2. European Commission. Preparing Teachers for Diversity: the Role of Initial Teacher Education: Publications Office of the European Union, Luxembourg; 2017 Retrieved from URL http://dx.doi.org/10.2766/061474.

3. Department for Education. Schools, pupils and their characteristics: Data Insight and Statistics Division; January 2018. Retrieved from URL https://www.gov.uk/government/statistics/schoolspupils-and-their-characteristics-january-2018

4. Burns $T$, Shadoian-Gersing V. The importance of effective teacher education for diversity. Retrieved from URL: https://www.oecd-ilibrary.org/education/educating-teachers-fordiversity/the-importance-of-effective-teacher-education-for-diversity 9789264079731-4-en

5. United Nations Educational, Scientific, and Cultural Organization, Paris (France). Guidelines for inclusion: Ensuring access to education for all. ERIC Clearinghouse; 2005. Retrieved from URL https://unesdoc.unesco.org/ark:/48223/pf0000140224

6. Burner T, Nodeland TS, Aamaas A. Critical perspectives on perceptions and practices of diversity in Education. Nordic Journal of Comparative and International Education (NJCIE), 2(1), 3-15. 2018

7. Bhopal K, Rhamie J. Initial teacher training: understanding 'race,'diversity and inclusion. Race Ethnicity and Education. 2014 May 27;17(3):304-25.

8. Cardona Molto MC, Florian L, Rouse M, Stough LM. Attitudes to diversity: a cross-cultural study of education students in Spain, England and the United States. European Journal of Teacher Education. 2010 Aug 1;33(3):245-64.

9. Dunne L, Kay V, Boyle R, Obadan F, Lander V. 'I love a curry': student-teacher discourse around 'race'and ethnicity at a UK university. Journal of Education for Teaching. $2018 \mathrm{Mar}$ 15;44(2):162-74.

10. Lo YC, Inoue K. Running Head: A Study of Preservice Teachersâ€ ${ }^{\mathrm{TM}}$ Perceptions toward Their Professional Education Training Regarding English Language Learners. Journal of Border Educational Research. 2013 May 16;10(1).

11. Dudovskiy J. The ultimate guide to writing a dissertation in business studies: a step-by-step assistance. Pittsburgh, USA. 2018 Jul. Retrieved from URL https://researchmethodology.net/research-methods/data-analysis/qualitative-data-analysis/

12. Huberman AM, Miles M, Saldana J. Qualitative data analysis: A methods sourcebook. Sage Publications Ltd(CA). 2014

13. Paine L. Orientation towards diversity: What do prospective teachers bring?. National Center for Research on Teacher Education, Michigan State University; 1990.

14. Act E. c. 15. London: The Stationary Office. 2010.

15. Department for Education. Teachers' Standards: London DfE; 2011 [cited 2019 May 1] Retrieved from URL https://assets.publishing.service.gov.uk/government/uploads/system/uploads/attachment dat a/file/665520/Teachers Standards.pdf

16. HM Government. Revised prevent duty guidance: For England and Wales. 2015

17. Luft J, Ingham H. The johari window. Human relations training news. 1961 Jan;5(1):6-7. 


\section{APPENDIX}

\begin{tabular}{|c|c|}
\hline Associate Teachers (ATs) & $\begin{array}{l}\text { The term associate teachers are referred to those students on } \\
\text { Initial Teacher Education Programme (ITE) }\end{array}$ \\
\hline Initial Teacher Education (ITE) & $\begin{array}{l}\text { Three year degree programme training ATs to become qualified } \\
\text { teachers }\end{array}$ \\
\hline Teacher educator (TEs) & $\begin{array}{l}\text { Teacher educators are those educational professionals who } \\
\text { actively facilitate the (formal) learning of ATs }\end{array}$ \\
\hline Black and Minority Ethnic (BME) & $\begin{array}{l}\text { Those pupils of all school age who have been classified } \\
\text { according to their ethnic group and are of any origin other than } \\
\text { White British are defined as being of minority ethnic origin. } \\
\text { BME is also a term used by OFS (Office for students - an } \\
\text { independent regulator of higher education in England) }\end{array}$ \\
\hline $\begin{array}{l}\text { English as an additional } \\
\text { language }(E A L)\end{array}$ & $\begin{array}{l}\text { A pupil is recorded to have English as an additional language if } \\
\text { shelhe is exposed to a language at home that is known or } \\
\text { believed to be other than English. }\end{array}$ \\
\hline $\begin{array}{l}\text { Office for Standards in Education } \\
\text { (OFSTED)/ education and } \\
\text { training inspectorate for Wales } \\
\text { (ESTYN) }\end{array}$ & $\begin{array}{l}\text { They monitor the quality of schools, colleges and children } \\
\text { services in England and Wales respectively. }\end{array}$ \\
\hline Newly Qualified Teacher (NQT) & $\begin{array}{l}\text { An NQT is a newly qualified teacher who has just obtained } \\
\text { attained Qualified Teacher Status (QTS), and is now undertaking } \\
\text { an induction programme that enables them to be legally } \\
\text { employed as a teacher in a maintained school. }\end{array}$ \\
\hline
\end{tabular}

